$1988 ; 3: 141-50)$.

Nous n'en sommes pas là et à l'heure actuelle l'analyse structurale du génome et l'identification des gènes qu'il contient constituent un préalable indispensable. Le brusque coup d'accélérateur que donne à cette recherche le développement de techniques très puissantes et l'ingéniosité que mettent les uns et les autres à exploiter ces nouvelles possibilités permettent de penser que d'ici un an ou deux nous aurons les réponses à beaucoup de questions actuellement posées, et sans doute de nouvelles questions que nous ne soupçonnons pas aujourd'hui!

Bertrand Jordan
Une isoenzyme de phosphatidylinositol-kinase catalyse la synthèse de phosphatidylinositol 3 phosphate (Ptd-Ins (3) P). Le Ptd-Ins $(4,5)$ P2 est le précurseur bien connu du diacylglycérol et de l'Ins P3, seconds messagers de nombreuses actions hormonales ou stimulées par les facteurs de croissance. Le Ptd-Ins est phosphorylé par deux isoenzymes de Ptd-Ins kinase, appelées I et II. La forme I est associée à plusieurs types de tyrosine-kinases, par exemple le récepteur du facteur de croissance PDGF et le complexe entre l'antigène moyen $T$ du virus polyome et le produit $\mathbf{P 6 0}{ }^{\text {r.src }}$, de l'oncogène c-src. En fait, il vient d'être démontré que cette isoenzyme I catalysait la synthèse de Ptd-Ins (3) $\mathrm{P}$ et non de Ptd-Ins (4) P. Le dérivé phosphorylé en 3 est un composant mineur représentant moins de $10 \%$ du Ptd-Ins (4) $P$ et rien n'est connu de son métabolisme ultérieur. Néanmoins, l'association de la Ptd-Ins kinase I avec des produits d'oncogènes suggère que le Ptd-Ins (3) P pourrait être impliqué dans le contrôle des phénomènes de prolifération cellulaire.

[Whitman M, et al. Nature 1988; 332 : 644-6.]

\title{
FLASH
}

\section{Structure de France-Transplant}

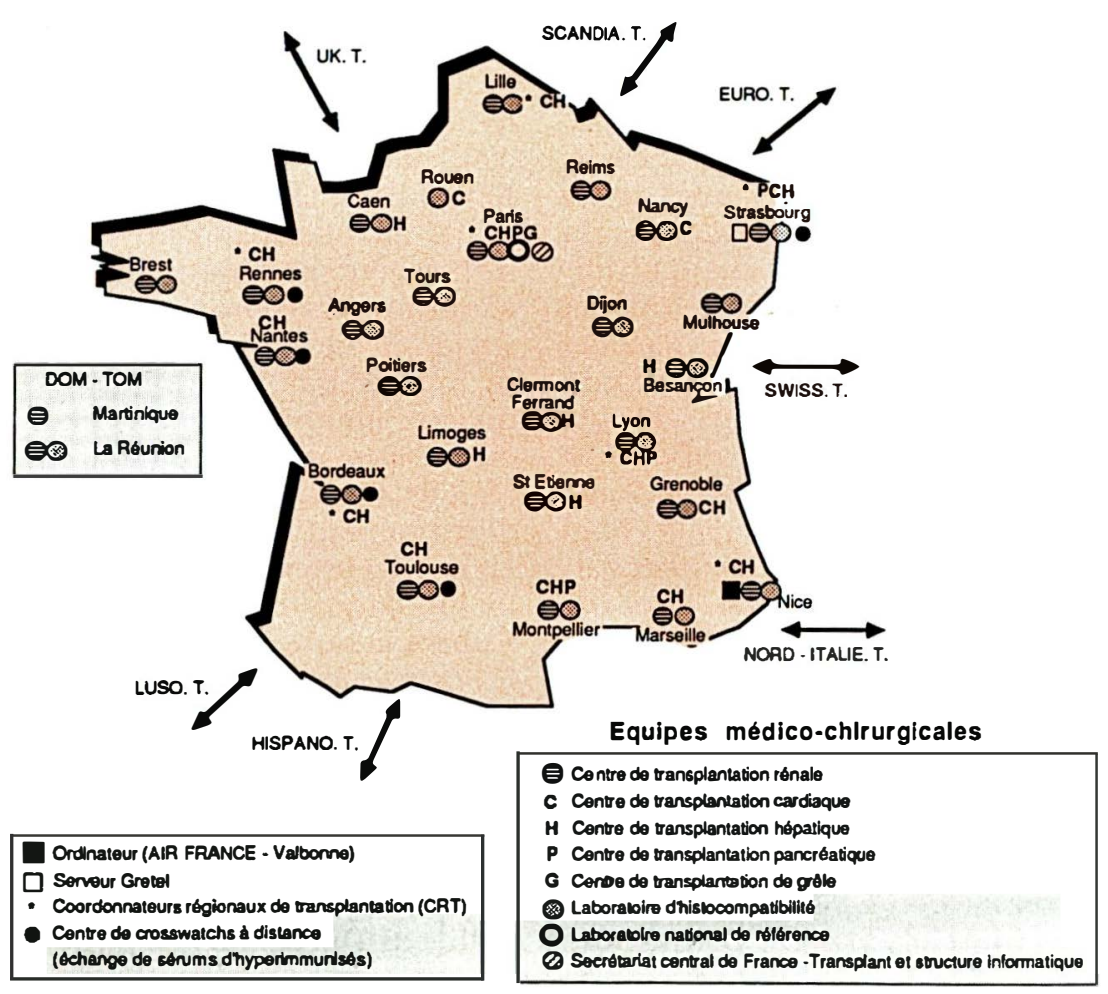

France-Transplant est une association Loi 1901, fondée le 23 septembre 1969 par Jean Dausset, reconnue d'utilité publique le 18 décembre 1978 et exclusivement subventionnée par le ministère de la Santé et la CNAMTS.

Elle regroupe l'ensemble des équipes de transplantation et de prélèvement, les laboratoires d'histocompatibilité et les coordonnateurs de transplantation, répartis sur le territoire national et reliés entre eux par un réseau télématique, initialement de type Télex puis récemment par Minitel et microordinateurs.

Au 31 décembre 1987, 91 équipes participent à l'effort national de transplantation : 39 pour les greffes de rein, 25 pour le coeur, 20 pour le foie, 5 pour le pancréas et 2 pour l'intestin grêle.

La réalisation des tests d'histocompatibilité (groupes HLA du donneur et du receveur, crossmatch en urgence) est assurée par 26 laboratoires. 